\title{
Parental Perception of Health-Related Quality of Life of Children [8-12 Years] Living with HIV
}

Abideen Salako, Agatha David, Babasola Opaneye, Kazeem Osuolale, Titilola Gbaja-Biamila ${ }^{1}$, Oluwatosin Odubela, Oluwakemi Adetayo, Tomilola Musari-Martins, Priscilla Ezemelue

Clinical Sciences Department, Nigerian Institute of Medical Research, Lagos, Nigeria

Correspondence: titigbajabiamila@yahoo.com; Tel.: + 2349092133886

Received: July 18, 2020; Accepted: December 12, 2020

\begin{abstract}
Objective - This study aims were to evaluate the parental perception of health-related quality of life (HRQoL) of children living with Human Immunodeficiency Virus (HIV) using the Pediatric quality of life questionnaire (PedsQL ${ }^{\mathrm{T} M}$ ), compare children's report with the parental proxy report, and examine the association of child-report with other socio-demographic and clinical characteristics. Methods - A cross-sectional study involved 39 children living with HIV on antiretroviral therapy (ART) and their parents who were recruited at the Nigerian Institute of Medical Research, Lagos. A validated PedsQL ${ }^{\mathrm{TM}}$ questionnaire with 23 items designed to measure four generic dimensions of health was used to collect data. The parental proxy report forms were filled by the parents/caregiver. The information obtained from the PedsQL ${ }^{\mathrm{TM}}$ questionnaire were analyzed using the scoring protocol of PedsQL ${ }^{\mathrm{TM}}$ version 4.0. Results - The mean age of the children was 10.6 \pm 3 years, with a male-to-female ratio of 1.2:1. The mean physical and overall HRQoL scores were significantly better in the child's self-report compared to parental proxy reports. There was significant association between the child self-report of HRQoL and parental proxy report (odds ratio [OR]=20, 95\%Confidence Interval [CI] 2.184-193.7), duration of ARTs $(\mathrm{OR}=11.455,95 \% \mathrm{CI}=1.22-107.51)$ and male gender $(\mathrm{OR}=0.156$, 95\%CI=0.038-0.38). Conclusion - Parental scores, male gender, and duration of ART were associated with better HRQoL outcomes in children living with HIV.
\end{abstract}

Key Words: Adolescent • Parents • Health-Related Quality of Life • HIV.

\section{Introduction}

The global incidence of HIV/AIDS [Human Immunodeficiency Virus/Acquired Immunodeficiency Syndrome] infection among children has been halved in the last two decades (1). Nevertheless, the burden of the disease remains high in sub-Saharan Africa despite the provision of antiretroviral therapy (ART) during pregnancy, breastfeeding, and the improvement in treatment coverage (1-3). Furthermore, the population of children with HIV surviving into adolescence and later adulthood is on the rise due to the availability of comprehensive universal care which includes ART (3-6).

Despite the increasing life expectancy and wellbeing among children living with HIV/AIDS on ART, these children and their parents/caregivers face numerous multifaceted physical, psychological and social challenges. Some of these include lifelong use of ARTs, adherence issues (7), long-term detrimental effects of ARTs (such as cancer, cardiovascular diseases, metabolic disorder) (8-11), stigmatization, disclosure issues, mood disorders, behavioral problems, oppositional defiant disorders,

$\stackrel{>}{ }$ ORCID: 0000-0003-2958-2924. 
bereavement, financial issues, social unacceptability, educational issues and lack of emotional support (12-15).

Subsequent consequences of these challenges have negative predictive effect on the parents/ caregivers, child living with HIV, and influence parents/caregivers' perception of the health outcomes of their children living with $\operatorname{HIV}(7,12,13$, $16,18)$. It is of utmost importance to continue to evaluate the well-being of children living with HIV using appropriate tools measuring the health status of children living with HIV as well as direct/ indirect effect on families to ensure positive health outcomes.

The Pediatric quality of life questionnaire (Ped$\left.s \mathrm{QL}^{\mathrm{TM}}\right)(18)$ is an important tool for the evaluation of health-related quality of life (HRQoL) of children. Being concise and having age-appropriate versions and parallel forms for child and parent are the advantages of PedsQL ${ }^{\mathrm{TM}}(19,20)$. The tool has shown distinguishing differences in measurements of HRQoL of healthy children, children with acute illnesses as well as chronic diseases (21-23). This questionnaire was originally developed in the United States. The PedsQL ${ }^{\mathrm{TM}}$ has been validated in various countries globally including Nigeria and has been used in different studies in the paediatric population worldwide (22-28).

Our study was conducted using the PedQL ${ }^{\mathrm{TM}}$ to evaluate HRQoL of children aged 8 to 12 years living with HIV and their parents, to compare healthrelated quality of life self-reported by children (Report from the view of the children) with the parental proxy perception of HRQoL and to examine the association between health-related quality of life selfreported by children living with HIV and parental proxy perception of HRQoL, controlled by sociodemographic and clinical characteristics of children.

\section{Methods}

\section{Study Design}

A cross-sectional design carried out over three months (May 2019-July 2019) at the Paediatric and Adolescent Clinic, Clinical Sciences Depart- ment at the Nigerian Institute of Medical Research Yaba, Lagos, Nigeria. The clinic offers comprehensive HIV care and treatment services to adults, adolescents, children, and pregnant women and has a cumulative enrolment of over 25,000 patients since the opening in 2002. The Paediatric Clinic runs on Friday every week, while the Adolescent Clinic is open every second Saturday of the month.

\section{Study Population}

A total of 39 children aged 8-12 years living with HIV/AIDS who have been receiving ART for at least three months and their parents'/caregivers were included in the study. The parents provided informed consent and children gave assent to participate in the study. Those children with comorbidities (cerebral palsy, seizure disorders, sickle cell anemia, hepatitis B/C), all newly diagnosed ALHIV, those receiving ART for less than 3 months, and those with acute illness were excluded. Middle childhood ( $8-12$ years) is a period that children start to experience changes in their lives in the form of puberty, increased academics demands (preparation to enter junior high or secondary school), increased peer relationships, and increased attention span. The initial phase of HIV disclosure occurs in this age-group as their school curriculum inculcates sexual and reproductive health. This provides us with an inkling of their perception to their wellbeing before being fully aware of their HIV diagnosis. There is a planned study for other age groups where outcomes can be compared.

\section{Study Procedure}

Children attending the clinic with their parents/ caregivers were randomly selected from the clinic database (using a table of random numbers generated by the biostatistician) and their eligibility for the study was assessed. The study was explained to parents/caregivers and children who met the study criteria by a member of the study team [clinician and designated counsellor]. Those who agreed to take part were taken through a detailed informed 
consent and assent process. After consent and assent were provided, participants were enrolled in the study. The case record form (CRF) was used to collect data on sociodemographic characteristic (age, sex, level of education if in school/ nature of job if out of school, family size/ birth order, parental HIV status, parental socio-economic class was calculated using the Oyedeji classification) (29). The age at diagnosis, current/previous antiretroviral therapy, duration of ART, current CD4 counts, and viral load were obtained from the clinic database. The duration of ART was classified into two groups with a 5year period as the cut-off point. Children were deemed to be clinically stable once they achieved CD 4 values $>500$ cells $/ \mathrm{mm}^{3}$ and Viral Load $<1000$ copies/ml. ART regimen of the children were combinations Nevirapine, Lamivudine and Zidovudine / Abacaviror Lopinavir, Lamivudine and, Tenofovir.

The quality of life assessment was performed using a pre-tested interviewer-administered Pediatric quality of life questionnaire (Peds $\mathrm{QL}^{\mathrm{TM}}$ ) (18). The tool is a robust 23-item questionnaire designed to measure four core dimensions of health: physical function (8 items), emotional functions ( 5 items), social function ( 5 items), and school functioning ( 5 items). Parental report forms were filled by parents/ caregivers of children included in the study. Permission to use the Peds $\mathrm{QL}^{\mathrm{TM}}$ was obtained from copyright owners before the study (18).

The following definition of terms was used; "Good Quality of Life - Overall/Physical/Psychosocial HRQoL aggregate score of $80-100$ ", "Intermediate Quality of Life- Overall/Physical/ Psychosocial HRQoL aggregate of $60-<80$ " and "Poor Quality of Life- Overall /Physical/Psychosocial HRQoL aggregate score of $<60$ ”.

\section{Ethics Statement}

Ethical approval was obtained from the Institutional Review Board (IRB) of the Nigerian Institute of Medical Research before the study. The testing was confidential, participation in the study was voluntary and anonymous. Participants were able to withdraw at any point during the study.

\section{Data Analysis}

Data was analyzed using SPSS version 23.0. Categorical data were summarized using proportions, while continuous variables were tested for normality. Normally distributed data were presented as mean with standard deviation, while the skewed data were summarized as median with interquartile range. The information obtained from the PedsQL ${ }^{\mathrm{Tm}}$ questionnaire were analyzed according to the scoring protocol of the PedsQL $\mathrm{L}^{\mathrm{TM}}$ version 4.0. The Likert scale was reversed scored and linearly transformed to a 0-100 scale as follows: $0=100,1=75,2=50,3=25,4=0$. The composite Health-related quality of life (HRQoL) and the HRQoL domains were represented as mean with standard deviation score. The degree of agreement between parental-proxy reports and children's self-report was assessed by comparing their respective percentages across the three categories the aggregate scores were further tested using simple logistic regression at $95 \%$ confidence interval while multivariate analysis was done for variables with a significant association with HRQoL. Statistical significance will be accepted at P-values $<0.05$.

\section{Results}

A total of 39 children living with HIV aged 8-12 years participated in the study. The mean age was $10.6 \pm 1.3$ years. Twenty-one $(53.8 \%)$ participants were male with a male-to-female ratio of 1.2:1. Most of the children were enrolled in primary school [22(56.4\%)], had two living parents [25(64.1\%)], and pertained to middle social economic class [19(48.7\%)]. Furthermore, the majority of the study participants at enrollment had viral suppression [34(87\%)], CD4 lymphocyte count of $\geq 500$ cells $/ \mathrm{mm}^{3}$ [36 (92\%)], and received first-line ART [30(76.9\%)] (Table 1).

\section{Quality of Life Scores}

The average self-reported HRQoL scores of children were the following: Physical Health status $75.7 \pm 29.2$, Psychosocial Health status $74.3 \pm 17.6$, and total perceived HRQoL 74.9.6 \pm 21.4 . Furthermore, children's self-report scores were better com- 


\begin{tabular}{|c|c|}
\hline Characteristics & Frequency $\mathrm{N}=39(\%)$ \\
\hline Age $($ Mean $\pm S D)$ years & $10.6 \pm 1.3$ \\
\hline \multicolumn{2}{|l|}{ Gender } \\
\hline Male & $21(53.8 \%)$ \\
\hline Female & $18(46.2 \%)$ \\
\hline $\mathrm{M}: \mathrm{F}$ & $1.2: 1$ \\
\hline \multicolumn{2}{|l|}{ Level of education } \\
\hline Primary & $22(56.4 \%)$ \\
\hline Secondary & $17(43.6 \%)$ \\
\hline \multicolumn{2}{|l|}{ Orphan status } \\
\hline Both parent alive & $25(64.1 \%)$ \\
\hline Double orphan & - \\
\hline Maternal orphan & $8(20.5 \%)$ \\
\hline Paternal orphan & $6(15.4 \%)$ \\
\hline \multicolumn{2}{|l|}{ Parental social class } \\
\hline Upper & $16(41 \%)$ \\
\hline Middle & $19(48.7 \%)$ \\
\hline Lower & $4(10.3 \%)$ \\
\hline \multicolumn{2}{|l|}{ ART regimen } \\
\hline First line therapy & $30(76.9)$ \\
\hline Second line therapy & $9(23.1)$ \\
\hline \multicolumn{2}{|c|}{ CD4 Lymphocyte (Count) } \\
\hline$\geq 500$ cells $/ \mathrm{mm} 3$ & $36(92.0)$ \\
\hline$<500$ cells $/ \mathrm{mm} 3$ & $3(8.0)$ \\
\hline \multicolumn{2}{|l|}{ Viral load } \\
\hline$\geq 1000$ copies $/ \mathrm{ml}$ & $5(13.0)$ \\
\hline$<1000$ copies/ml & $34(87.0)$ \\
\hline \multicolumn{2}{|l|}{ Art duration } \\
\hline$>60$ months & $32(82.1)$ \\
\hline$\leq 60$ months & $7(17.9)$ \\
\hline
\end{tabular}

pared to perceived parental HRQoL scores across all domains (Table 2).

\section{Degree of Concordance of Child Self-report with Parental Proxy Report}

Thirty-nine children were evaluated in the study and $32(82 \%)$ parents provide complete information. Twenty children $(51 \%)$ had good physical health scores with 12 (60\%) parental proxy reports being completely concordant, 7 (22\%) rated their

\begin{tabular}{llll}
\multicolumn{4}{l}{ Table 2. Quality of Life Scores } \\
\hline $\begin{array}{l}\text { Quality } \\
\text { of domains }\end{array}$ & $\begin{array}{l}\text { Child } \\
\text { self report }\end{array}$ & $\begin{array}{l}\text { Parents } \\
\text { proxy-report }\end{array}$ & $\mathrm{P}^{\dagger}$ \\
\hline Physical & $75.7 \pm 29.2$ & $60.5 \pm 34.2$ & 0.04 \\
\hline Psycho-social & $74.3 \pm 17.6$ & $69.5 \pm 22.4$ & 0.31 \\
\hline Overall Mean & $4.9 \pm 21.4$ & $64.8 \pm 26.6$ & 0.08 \\
\hline
\end{tabular}

${ }^{*} \mathrm{Mean} \pm \mathrm{SD}$; ${ }^{\dagger}$ Independent t-test.

children intermediate and one (3\%) rated the child as poor. Four children (10\%) with intermediate physical health scores had two parental (6\%) proxy reports of concordance and two(6\%) being discordant (one being good and the other poor). Eight children $(21 \%)$ had poor physical health scores with a significant level $(87.5 \%)$ of parental proxy concordance while the discordant parental proxy rated the child as being intermediate.

Among children with good psychological health scores, 11(34\%) of the parental scores were in concordance while the remainder rated their wards as being intermediate. $12(31 \%)$ children had intermediate psychological health scores with $6(19 \%)$ of the parents in agreement while others assessed their children as being good (16.7\%) and poor (33.3\%). There was total agreement $(100 \%)$ regarding parental and child reports regarding poor psychological health score

A total number of 19 children were adjudged to have an overall good HRQoL score in the study. 12 (63.2\%) parental proxy reports concurred with the child scores while the discordant scores were all adjudged to be poor. Among children with intermediate overall scores, $66.6 \%$ (4) parental proxy scores were in agreement while the others rated their wards as being good (16.7\%) and poor (16.7\%). Children with poor overall HRQoL scores (7) had $100 \%$ concordance with parental scores (Table 3).

There was a significant association of gender (male) (Odds Ratio [OR] $=0.156,95 \%$ Confidence Interval $[95 \% \mathrm{CI}]=0.038-0.638)$, duration of ARTs (>60months) (OR=11.45 CI1.22-107.51) and good parent-proxy HRQoL report $(\mathrm{OR}=20$ $\mathrm{CI}=2.814-193.7)$ with children's better self-reported HRQoL. A child was more likely to report better HRQoL scores, if they were boys, had been receiving therapy for $>60$ months, and if parental-proxy report rated their HRQoL as 'good' (Table 4). 


\begin{tabular}{|c|c|c|c|c|c|c|c|c|}
\hline \multirow[b]{2}{*}{ Variable } & \multicolumn{2}{|c|}{ HRQOL Report } & \multicolumn{3}{|c|}{ Univariate $^{*}$} & \multicolumn{3}{|c|}{ Multivariate $^{\dagger}$} \\
\hline & $\begin{array}{l}\text { Good } \\
(\mathrm{N}=22)\end{array}$ & $\begin{array}{l}\text { Intermediate/ } \\
\text { Poor }(\mathrm{N}=17)\end{array}$ & $\mathrm{OR}^{\ddagger}$ & $95 \% \mathrm{CI}^{\S}$ & $\mathrm{P}^{\|}$ & $\mathrm{OR}^{\ddagger}$ & $95 \% \mathrm{CI}^{\S}$ & $\mathrm{P}^{\|}$ \\
\hline \multicolumn{9}{|l|}{ Gender } \\
\hline Males & $16(72.7)$ & $5(29.4)$ & \multirow{2}{*}{0.156} & \multirow{2}{*}{$0.038-0.638$} & \multirow{2}{*}{0.005} & \multirow{2}{*}{0.274} & \multirow{2}{*}{$0.055-1.356$} & \multirow{2}{*}{0.113} \\
\hline Female & $6(27.3)$ & $12(70.6)$ & & & & & & \\
\hline \multicolumn{9}{|l|}{ Viral Load (copies/ml) } \\
\hline$<1000$ & $21(95.5)$ & $13(76.5$ & \multirow{2}{*}{6.462} & $0.213-0.428$ & \multirow{2}{*}{0.06} & \multirow{2}{*}{2.640} & $0.183-8.353$ & \multirow{2}{*}{0.488} \\
\hline$\geqq 1000^{* *}$ & $1(4.5)$ & $4(23.5)$ & & $0.649-64.312$ & & & $0.170-40.998$ & \\
\hline \multicolumn{9}{|l|}{ Duration on ART } \\
\hline$\leq 60$ months & $1(4.5)$ & $6(35.3)$ & \multirow{2}{*}{11.455} & \multirow{2}{*}{$1.22-107.51$} & \multirow{2}{*}{0.02} & \multirow{2}{*}{6.374} & \multirow{2}{*}{$0.522-77.773$} & \multirow{2}{*}{0.147} \\
\hline$>60$ months & $21(95.5)$ & $11(64.7)$ & & & & & & \\
\hline \multicolumn{9}{|l|}{ CD4 (Count cells/mm³) } \\
\hline$<500^{\dagger \dagger}$ & $1(4.5)$ & $2(11.8)$ & \multirow{2}{*}{2.880} & \multirow{2}{*}{$0.232-33.79$} & \multirow{2}{*}{0.20} & \multirow{2}{*}{0.914} & \multirow{2}{*}{$0.026-32.263$} & \multirow{2}{*}{0.960} \\
\hline$\geqq 500$ & $21(95.5)$ & $15(88.2)$ & & & & & & \\
\hline \multicolumn{9}{|l|}{ Parental proxy report ${ }^{\ddagger \ddagger}$} \\
\hline Good & $12(63.2)$ & $1(7.7)$ & \multirow{2}{*}{20} & \multirow{2}{*}{$2.184-193.7$} & \multirow{2}{*}{$<0.004$} & \multirow{2}{*}{-} & \multirow{2}{*}{-} & \\
\hline Intermediate/Poor ${ }^{\S \S}$ & $7(36.8)$ & $12(92.3)$ & & & & & & - \\
\hline
\end{tabular}

"Test statistics is Chi-square test; ${ }^{\dagger}$ Test statistics is Logistic regression; ${ }^{\ddagger}$ Odds Ratio; ${ }^{\circledR}$ Confidence Interval; "Significant P-value $<0.05$; ${ }^{\circ}$ Reference value for gender; " Reference value; ${ }^{\dagger \dagger}$ Reference value (Score); ${ }^{\ddagger \ddagger}$ Filled by parents; ${ }^{\circledR \varsigma}$ Reference value (Score).

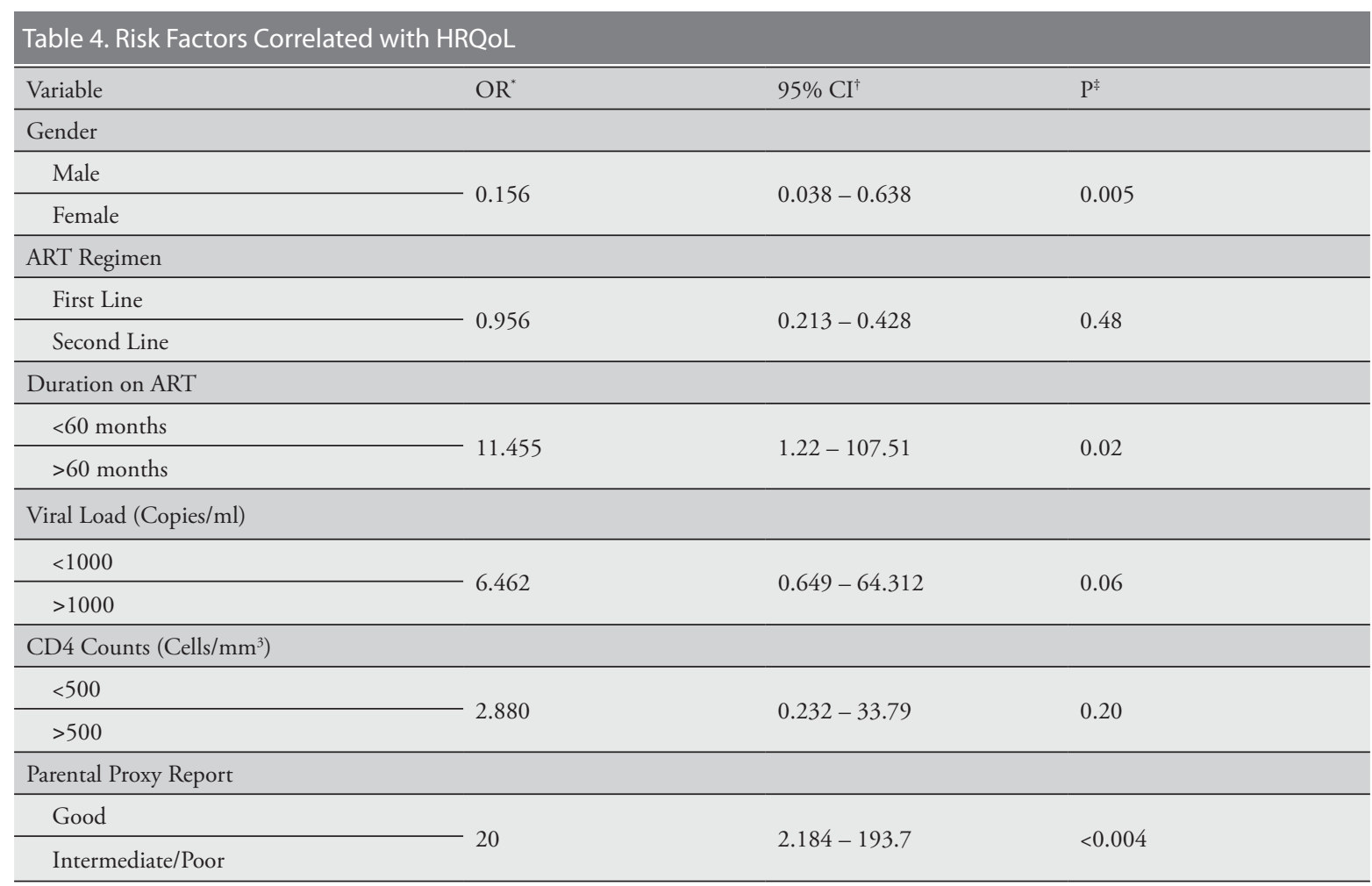

"Odds Ratio; ${ }^{\dagger}$ Confidence Interval; ${ }^{\ddagger}$ Chi-square test. 


\section{Discussion}

Accessibility and availability of ART as well as comprehensive HIV care services have changed the landscape of HIV/AIDS from an acute fatal illness to chronic illness, thus ensuring children's survival to an older age. This study showed a high rate of concordance between good HRQoL scores between the self-reported child and parental proxy scores. A better HRQoL outcome was associated with being males and on ART for more than sixty months.

The predominant proportion of children evaluated in the current study had parental support, good immunological status with respect to viral suppression, and CD4 count, with their HRQoL scores similar to reports by Das et al. (30) and Gopakumar et al. (28) in India. The scores can be contributed to by the ease of accessibility of ART and comprehensive HIV care. Higher physical HRQoL score compared to psychosocial score in the current study suggests that children living with HIV are subjected to emotional or socio-behavioural distress. There are several potential explanations for this finding. First, children may lack an understanding of the reasons for continuous need to use ART. Second, they may be absent from school due to routine clinic visits. Third, parents likely impose on their children limitations during activities of daily living. Fourth, children may occasionally experience feelings of dysphoria because of the illness they know little about. Fifth, there might be poor parent-child relationships and children may have the perception to be continuously unhealthy $(7,12,13)$. Our results confirm previous evidence about the poor psychological wellbeing of children and adolescents who live with HIV. Lower psychosocial scores observed in this study are in accordance with reports of other researchers who studied children living with $\operatorname{HIV}(28,30-35)$. Although Gupta et al. (27) reported better psychosocial HRQoL in the study population in South India suggesting that this difference might be due to family and socio-cultural practices in the community.

The parental-proxy reports regarding the overall health, physical, and psychosocial domains were lower compared to that of the children. Neverthe- less, we did observe the association between parental-proxy reports and children's reports, which means that parental perception of a child's health can be an accurate indicator of child's status. Potential explanations for the parental-proxy reports could be a negative life event among parents of children living with HIV/AIDS. For example, parental self-criticism, anxiety, burden of secrecy, guilt, bereavement, financial challenges, and the fact that HIV is being stigmatized in their community could be distressing and counteract their physical and psychosocial wellbeing $(12,13,16,17)$. Parental reports affirm family perception of children living with $\operatorname{HIV}(27,28,30-35)$, suggesting the need for continuous psychosocial support of parents/families living with HIV.

In this study, we observed that age, gender, orphan status, type and duration on ART, immunological status (viral load and CD4 lymphocyte count) as well as parental-proxy report were relevant for the HRQoL outcomes of children, even though only male gender, duration of ART and perceived parental reports were found to be associated with better HRQoL in children.

Better HRQoL reports were associated with the male gender. This may be a reflection of the role and perception of a male child given the socio-cultural norms, lower levels of internalizing negative emotions such as anxiety, sadness, or physical challenges compared to females (36-38). This requires further evaluation in future studies among children. Association of longer duration of ART with favorable HRQoL was similar to report by the PREDICT study in Southeast Asia (34). However, the finding in this study disagrees with some previous findings across different age groups where the association between age and HRQoL was not found $(27,28$, $30,35)$. Furthermore, although most of the study participants had two living parents, good immunological status [CD4 lymphocyte count, viral load] there was no significant association between social status, immunological status, and better HRQoL, suggesting that other factors play a more important role for the well-being of children living with HIV. These findings support the results from previous 
studies $(27,28,30,35)$. The strength of this study is the in-depth data obtained about the views of HRQoL obtained from both parents and children. It is one of the first studies to be done in western Nigeria where both parents and children views are accessed.

\section{Study Limitations}

Limitation of this study is a cross-sectional design. The small sample size is a limitation as there could be higher variability and thereby some bias in the results. Future work should include a prospective follow-up of a cohort of children living with HIV. In this way, it would be possible to distinguish specific psychosocial and mental health challenges that children and the families encounter as well as their coping mechanisms.

\section{Conclusion}

In conclusion, we found that parental-proxy reports of their children's HRQoL were lower compared to self-reports of children. Being boys, duration of ART as well as better parental perception of their children's HRQoL were significantly associated with self-perceived HRQoL in children living with HIV. As the HIV care services continue to evolve there is the need to ensure prompt and continuous psychosocial support to children living with HIV to promote their health and well-being.

Acknowledgements: We are appreciative of the children and the parents/caregivers who participated in the study and who continue to trust the Paediatric team of the clinical science department of the Nigerian Institute of Medical Research with the care of the children. Our sincere gratitude to the Nursing unit, the Counselling units [Mrs. Oresegun, Miss Queen Ejiga and Head of Unit Dr. Ifeoma Idigbe], the Data and Monitoring team [especially Mr. Oba and Mrs. Odubela among other unit members] for the support always.

Conflict of Interest: The authors declare that they have no conflict of interest.

\section{References}

1. UNAIDS. Global AIDS Update 2018 Miles To Go: Closing Gaps Breaking Barriers Righting Injustices. UNAIDS
[Internet]. 2018 [cited 2020 Jun 27] Available from: http://www.unaids.org/en/resources/documents/2018/ global-aids-update.

2. World Health Organization. Number of people (all ages) living with HIV. Global Health Observatory (GHO). 2018 [cited 2020 Jun 27]. p. 1-3. Available from: https:// www.who.int/gho/hiv/epidemic_status/cases_all_text/en/.

3. National agency for the control of AIDS(NACA).National Strategic Framework on HIV and AIDS: 2017-2021 - NACA Nigeria [Internet]. 2020 [cited 2020 Dec 27]. Available from: https://naca.gov.ng/2013-national-hivvalidated-data-2-2/.

4. Mahy M, Penzazato M, Ciaranello A, Mofenson L, Yianoustsos T.Constantin, et al, Improving estimates of children living with HIV from the Spectrum AIDS Impact Model. AIDS. 2017; 31(Suppl 1);13-22.

5. Davies M, Gibb D, Turkova A. Survival of HIV-1 vertically infected children. Curr Opin HIV AIDS. 2016;11(5);455-64.

6. Shabangu P, Beke A, Manda S, Mthethwa N. Predictors of survival among HIV-positive children on ART in Swaziland. Afr J AIDS Res. 2017;16(4):335-43.

7. Oguntibeju OO. Quality of life of people living with HIV and AIDS and antiretroviral therapy. HIV AIDS (Auckl). 2012;4:117-24

8. World Health Organization. HIV/AIDS: Chronic comorbidities and co-infection in PLHIV.WHO database 2020 [cited 2020 May 20] Available at http://www.who.int/hiv/ topic/comorbidities/en/.

9. Hasse B, Ledergerber B, Furrer H, Battegay M, Hirschel B.et al. Morbidity and aging in HIV-infected persons: The Swiss HIV cohort study. Clin Infect Dis. 2011;53(11):1130-9.

10. Guaraldi G, Zona S, Brothers TD, Carli F, Stentarelli C. et al. Aging with HIV vs. HIV seroconversion at older age: a diverse population with distinct comorbidity profiles. PLoS One. 2015;13(10):1-11.

11. Mutimura E, Crowther NJ, Stewart A, Cade TW. The Human Immunedeficiency Virus and the Cardiometabolic Syndrome in the Developing World: An African Perspecctive. J Cardiometab Syndr. 2008;3(2):106-10.

12. Vranda MN, Mothi SN. Psychological Issues of Children Infected with HIV/AIDS. Indian J Psychol Med. 2013:35(1):19-22.

13. Brown LK, Lourie KJ, Pao M. Children and adolescents living with HIV and AIDS: a review. J Child Psychol Psychiatry. 2000:41(1):81-96.

14. Alford K, Vera J H. Cognitive impairment in people living with HIV in ART era: A Review. British Medical Bulletin. 2018:12(1):55-68. 
15. Epstein LG Sharer LR. Neurological manifestations pf perinatally acquired HIV-1 infection. Semin Pediatr Neurol. 1994:1(1):50-7.

16. Fawzi MCS, Eustache E, Oswald C, Surkan P, Louis E, Scanlan F, Wong R et al. Psychosocial Functioning Among HIV-Affected and Their Caregivers in Haiti: Implication for Family-Focused Service Provision in High HIV Burden Settings. AIDS Patient Care STDS. 2010;24(3):147-58.

17. Kaplan M. Psychosocial issues of Children and families with HIV/AIDS. Occup Ther Health Care. 1991:7(24):139-49.

18. Mapi Research Trust. Mapi Research Trust; ePROVIDE. The Pediatric quality of life questionnaire (PedsQLTM). Approved for use on May 3 2019. PROQOLID/ePROVIDE [Internet]. 2019 [cited 2020 Jun 27]. Available from: https://www.google.com/search?q=18.+Mapi+Research $+\mathrm{T}$ rust $\% 3 \mathrm{~B}+$ ePROVIDE. + The+Pediatric+quality+of +life+qu estionnaire+(PedsQLTM).+Approved+for+use+on+May+ $3+2019 . \&$ oq $=18 . \% 09 \mathrm{Mapi}+$ Research + Trust $\% 3 \mathrm{~B}+\mathrm{ePRO}$ VIDE.+The+Pediatric+quality+of+life+questionnaire+(Pe $\mathrm{d} s \mathrm{QLTM})$.+Approved +for+use+on+May+3+2019.\&aqs=c hrome..69i57.1283j0j4\&sourceid=chrome\&ie=UTF-8

19. Eiser C, Morse R. Quality-of-life measures in chronic diseases of childhood. Health Technol Assess. 2001;5(4):1157.

20. Varni JW, Seid M, Rode CA. The PedsQL: measurement model for the pediatric quality of life inventory. Med Care. 1999;37(2):126-39.

21. Varni JW, Burwinkle TM, Seid M. The PedsQL 4.0 as a school population health measure: feasibility, reliability, and validity. Qual Life Res. 2006;15(2):203-15.

22. Varni JW, Seid M, Kurtis PS.PedsQL 4.0: reliability and validity of the Paediatric Quality of life Inventory version 4.0 generic core scales in healthy and patient population. Med Care. 2001;39(8):800-12.

23. Varni JW, Burwinkle TM, Seid M, Skarr D. The PedsQL 4.0 as a pediatric population health measure: feasibility, reliability and validity. Ambu Pediatr. 200;3(6)329-41.

24. Lagunju I A, Akinyinka O, Orimadegun A, Akinbami F O, BrownB J, et al., Health-Related Quality of Life of Nigerian children with epilepsy. AJNS; 2009;28:1-7.

25. Atilola, O., \& Stevanović, D. PedsQLTM 4.0 Generic Core Scales for adolescents in the Yoruba language: Translation and general psychometric properties. Clinical Child Psychology and Psychiatry. 2013;19(2):286-98.
26. Ayuk AC, Oguonu T, Ikefuna AN, Ibe BC. Asthma control and quality of life in school- age children in Enugu south east, Nigeria. The Nigerian Postgraduate Medical Journal. 2014;21(2):160-4.

27. Gupta M, Nanda S, Shankar K. Quality of Life in Symptomatic HIV-infected children. Indian Paediatrics.2013:50:1145-7.

28. Gopakumar KG, Bhat KG, Shetty AK. Health -Related Quality of life if children with HIV infection-A CrossSectional Study from South India. J Pediatr Infect Dis. 2017:12:104-9.

29. Oyedeji GA. Socio-economic and Cultural background of hospitalized children in Ilesha. Nig J Pediatr. 1985;12:1117.

30. Das S, Mukhrejee A, Lodha R, Vatsa M. Quality of Life and Psychosocial Function of HIV -infected children. Indian J Pediatr. 2010:77(6):633-7.

31. Banerjee T, Pensi T, Banerjee D. HRQoL in HIV-Infected children using PedsQL ${ }^{\mathrm{TM}} 4.0$ and Comparison with uninfected children. Qual Life Res. 2010:19:803-12

32. Lee MG, Gortmaker LS, McIntosh K, Hughes MD, Oleske JM. Quality of Life of Children and Adolescent: Impact of HIV infection and Antiretroviral Treatment. Pediatrics. 2006:117:273-83

33. Oberdorfer P, Loutherenoo O, Puthanakat T, Sirisanthana V, Sirisanthana T. Quality of Life Among HIV-Infected Children in Thailand. Journal of the International Association of Physicians in AIDS Care. 2008:7(3):141-7.

34. Bunupuradah T, Kosalaraska P, Vibol U, Hansudewechakul R, Sophonphan J, Kanjanavanit $S$ et al. Impact of Antiretroviral Therapy on Quality of Life in HIV-Infected Southeast Asian Children in the PREDICT study. AIDS Patient Care STDS. 2013:27(11):596-603.

35. Aurpibul L, Oberdorfer P, Choeyprasert W, Louthrenoo O. Health-related quality of life of perinatally HIV-infected adolescents. Curr Pediatr Res. 2016; 20 (1\&2): 231-7.

36. Chaplin TM. Gender and Emotion Expression: A Developmental Contextual Perspective. EmotRev. 2015:7(1):1421

37. Chamaz K. Identify dilemmas of chronically ill men. In; Sabo D, Gordon D. Men's health and illness: gender, power and the body, v8. London Sage; 1995: pp. 266-91.

38. Prout A. Sickness as dominant symbol in life course transitions: an illustrated theoretical framework. Social Health Illn. 1989:11(4):336-59. 
Commentary

Invited Commentary

Central Eur J Paed 2021;17(1):16-17

DOI: $10.5457 / \mathrm{p} 2005-114.282$

\section{Tracking Menstrual Cycle Using Smartphone Apps}

Jelena Dotlic

Clinic of Gynaecology and Obstetrics, Clinical Centre of Serbia, Faculty of Medicine, University of Belgrade, Serbia

Correspondence: drenadot@gmail.com; Tel. + 38163322782

Received: January 13, 2021; Accepted: January 16, 2021

Key Words: Smartphone Applications - Menstrual Cycle Tracking - Adolescent Girls.

In the last issue of Central European Journal of Pediatrics, Gazibara et al. explored the usage and factors associated with smartphone apps to track menstrual cycle (1). This study found that approximately one third of high school girls reported using menstrual cycle tracking apps. The girls who used smartphone apps to track menstrual cycle were more likely to use other Internet platforms such as Wikipedia, health forums, websites run by physicians as well as smartphone apps for fitness. Moreover, high school girls who used menstrual cycle tracking apps were mostly studying humanities-languages program and came from families in which parents had higher education and income levels (1).

Bearing in mind that adolescent girls frequently have irregular and longer menstrual cycles, tracking periods in this population is important in order to get the impression about their hormonal status and a potential need for therapy as well as to prevent unwanted pregnancy (2). Menstrual cycle tracking apps could provide a comprehensive chart of menstrual periods over time and could, therefore, be a suitable and effective method for young girls to get ready for the forthcoming menstruation. Moreover, the data collected by the app could be used by the gynecologists who have adolescent patients (3). Nevertheless, attention to app reliability ought to be paid before its use.
The app can be considered as accurate if:

- The projections of future menstrual cycles take into account the mean length of at least three previous menstrual cycles,

- Ovulation is accurately predicted i.e. around 14 days before the beginning of the next period,

- The app includes information about both conception and contraception, and

- If it is comprehensible and easy to use and does not provide any false information (4).

A technically versatile app should be protected with password, not need Internet connection, have no commercials or endorsements, provide medical and technical support within the app and include scientific literature (4). From the results obtained by Gazibara et al, it is noticed that in Serbia, although the vast majority of adolescent girls use smartphones, only $29.7 \%$ of female high school students use apps to track menstrual cycle $(1,5)$.

Therefore, it seems that more education regarding new technologies is needed to help women optimize their health. Such education could be a part of biology curricula in high schools in Serbia. In fact, it would be especially worthwhile that these educational programs include specifically adolescent girls of lower socioeconomic status and who have parents with lower education level. 


\section{References}

1. Gazibara T, Cakic J, Cakic M, Grgurevic A, Pekmezovic T. High school girls and smartphone applications to track menstrual cycle. Central Eur J Paed. 2020;16(2):132-39.

2. Kernoff Mansfield P, Stubbs ML. Tracking the course of menstrual life: contributions from the Society for Menstrual Cycle Research. Womens Health Issues. 2004;14(6):174-6.

3. Bull JR, Rowland SP, Scherwitzl EB, Scherwitzl R, Danielsson KG, Harper J. Real-world menstrual cycle charac- teristics of more than 600,000 menstrual cycles. NPJ Digit Med. 2019. doi: 10.1038/s41746-019-0152-7.

4. Moglia ML, Nguyen HV, Chyjek K, Chen KT, Castano PM. Evaluation of smartphone menstrual cycle tracking applications using an adapted applications scoring system. Obstet Gynecol. 2016;127(6):1153-60.

5. Statistical Office of the Republic of Serbia. Use of information-communication technologies in the Republic of Serbia. Household, individuals, enterprises. 2017. [cited 2021 January 9] Available from https://publikacije.stat. gov.rs/G2017/Pdf/G20176006.pdf 